\title{
Employee Experience Management of Convenience Store in Beijing
}

\author{
Jing Guo and P.L. Patrick Rau \\ Institute of Human Factors \& Ergonomics \\ Beijing, China \\ \{Guojing360, rpl\} @mail.tsinghua. edu.cn
}

\begin{abstract}
This article explores the occupational experiences of convenience store frontline service employees in Beijing. The results of our in-depth interview illustrate that there are some human factor issues in the experience of the employees, such as material handling, graveyard shift, ease of being injured, low salary, lack of career perspectives and unfair rules. We suggest that future researches should pay more attention to improve the experience of the employees, as their experience is directly related to their interaction with the customers as well as the service satisfaction of the customers.
\end{abstract}

Keywords: Convenience, frontline service employees, experience, in-depth interview.

\section{Introduction}

The convenience store originated in the United States in 1920s and the first convenience store was opened in 1946 which was named 7-Eleven. Because of its own characteristics such as in the center of downtown, providing a wide variety of products and services, 24 hours a day, convenience stores are playing a more and more important roles all over the world these years.

Convenience store of Beijingdeveloped late, but it is developing rapidly recent years. In 2004, there were only 13 convenience stores in Beijing, but now there are more than 1000 of varied convenience. Take 7-Eleven as an example, in 1994 there were only 5 7-Eleven in Beijing and today there are total 100 7-Eleven stores. Because of its convenience, the development of convenience store is of great significance to Beijing. China Chain Store \& Franchise Associationinvestigated115 top management of China chain industry and found that the most promising retail is convenience store[1].

Generally speaking, the work in convenience store is thought to be easy, labor intensive and monotonous and the frontline service employees don't need special skills and high competence. However, after deep interview of the frontline service employees, we found that their work is far more complex than our hypothesis.

The frontline service employees have to master interpersonal skills which influence customer satisfaction greatly. For instance, the displays of courtesies, friendliness and efficient service delivery will make the customers satisfied while lack of 
them would make the customers annoyed and disappointed. What is more, they may meet different kinds of customers, including the disrespected and the unreasonable. In this case they must put up with these customers and adjust their moods. So it is also necessary for them to master emotional management skills.

\section{Literature Review}

As the idea of service has greatly changed and the retail environment has changed rapidly, Customer experience is becoming more and more important. In recent years, managers have been increasingly aware of the importance to create value for their customers in terms of experiences. Creating excellent customer experience seems to be one of the critical objectives in today's retailing environments [3]. Convenience stores, as the most promising form of the retailers, are also trying their best to improve customers' experience. For instance, researchers have developed a large number of scales to evaluate the customers' experience and satisfaction, such as SERVQUAL, RSQ and so on. However, previous researches mostly focused on customers and seldom pay attention to the experience of frontline service employees [4].As a matter of fact, as Mohr and Bitnerand Katz pointed out, the experiences of frontline service employees should be considered as a critical component in the overall service experience [5].Improving the experience of frontline service employees is as important as upgrading the customers' experiences. The convenience store experience is conceptualized into the following four dimensions: (1) physical environment, (2) products, (3) service procedures, (4) frontlineemployee. The framework provides us with new perspectives for researching how interactions between customers and employees in the convenience stores.

In general, we use the method of job crafting to capture the actions employees take to shape, mold, and redefine their jobs. Those who actively compose both what their job is physically, by changing the job's task boundaries, what their job is cognitively, by changing the way they think about the correlations among job tasks, and what their job is relationally, by changing the interactions and relationships they have with others at workare called job crafters [6]. Job crafting is a psychological, social as well as physical act, in which cues are read about physical boundaries of the job and are explained by motivated crafters. Job crafters act upon the task and relational boundaries of the job, changing their identity and the significance of the jobduring this process. By doing so, job crafters create different jobs for themselves, within the context of defined jobs[7]. So that job crafting is a creative process which captures how individuals gradually get used to their jobs from the point of view of creating and sustaining a viable definition of the work they are doing and who they are working for [8].

Job crafting changes the meaning of the work through changing job tasks and relationships because it allows employees to redefine the purpose of the job and experience the work differently [9].Job crafting may also reshape one's work identity. And as we know, the reasons for shaping a work identity are basic. Individualstry their best to establish social communities that support desirable images of themselves [10]. 


\section{Methodology}

We carried out the research through various datacollection methods, including field investigation, in-depthinterviews. In the first stage, we use field method to investigate 11 convenience stores (7-Eleven) in different districts of Beijing. In the second stage, we interviewed 10 convenience stores' frontline service employees from two store locations.

\subsection{Subjects}

10 subjects (4 male and 6 female, mean age: 24.9) who is working at convenience stores (7-Eleven) in Beijing. Our sample contains different positions in convenience stores: 1sale manager, 2 assistant store managers, 1 store monitor, 1 salesclerk, 3 parttime employees for day shift and 2 part-time employees for night shift. The sample was purposive, non-random which invited convenience stores' employees from two different stores who are interested in the study and are pleased to join our interview.

\subsection{Process}

We started our in-depth interview in Jan 7th and ended it in Jan 21st. We went to 5 convenience stores (7-Eleven) to invite employees for our interview, but only 2 stores are interested in our study and would like to join our interview. The interview for every employee lasted around one hour.

The interview outline was draw up according to job crafting which refers to their works, emotions, customer interactions, lines, space /layout and so on. As a result, we could have a comprehensive understanding of the frontline service employees' daily work.

\section{Results}

From the perspective of human factors, there are some possible issues in the convenience employees' experience, including physiological human factors, cognitive human factors and organizational human factors. In the following, we will discuss these issues respectively.

\subsection{Physiological Human Factors}

For all the retail stores, the universal problem is material handling. They have to constantly update products so that the frontline service employees must deal with material handling every day. If you know nothing about material handling, it is possible that you may hurt you joint. One worker mentions:

One night we added nearly 50 boxes of water, and I had to handle all these by myself. So I was handling and handling, all the time. I really felt exhausted and had a back pain after finishing it. However, you have to do it as long as you work at the convenience store. (Male, 24s, part-time) 
Despite it, convenience stores are distinguishable from other retail setting for their providing fast food and running for 24 hours a day. As a result, they are heavier workload comparing to other retail setting employees. What's worse is that night shift makes you very tired and sleepy; moreover it is a danger to your health. One employee explains:

To be honest, I don't like working graveyard shift. First of all, you are quite sleepy when working; especially form 23 o' clock to 01 o' clock. Further, it completely reverses your life from normal. You are sleeping when all the others are working and when they are sleeping, you are working. There is no doubt that graveyard is harmful to your health. After working graveyard for about 1 year, now I seldom eat lunch and sometimes felt headache. (Male, 24s, parttime)

\subsection{Cognitive Human Factors}

Although the work in convenience store is thought to be easy, labor intensive and monotonous, in fact it is not the case. First, they have to work under stress. The stress comes when there are a lot of customers waiting in line, when they have to accomplish the sale target for special products in festivals. Furthermore, they have to pay for the loss if they make a mistake when checking out.And they are afraid of the products to be stolen. One assistant store manager describes:

I felt particularly anxious when a great many customers were waiting in line, maybe 40 to 50 customers in rush hour. I hurried up to check out as well as comforted the customers. If some customer is impatient and get angry with, you can't quarrel or even explain to him/her. You can't answer him back no matter whether he is right or wrong, or no matter how rude and unreasonable he is. The only thing you can do is just to ignore him or apologize to him. In a word, you can't exhale your emotions and you can't be yourself when you are at work. (Female, 24s, assistant store manager)

Second, they have to put up with varied impatient and rude customers. Third, their works are all chores, so it is easy for them to get distracted. Fourth, they have to do the monotonous repetitive work every day and their job is inferior in social position. Last but not least, they are likely to be complained if the customer is unsatisfied with them. In this situation, it will be very hard for them to be promoted both in their position and salary.

\subsection{Organizational Human Factors}

Even if the employees have occupational skill training before work, it is easy for them to get injured at work. For example, you may be scalded by the soymilk machine; you may be scratched by the banknotes; you may be bruised by the storage shelves. A store monitor says: 
For us, it is normal to be injured when working, perhaps 2 or 3 times a month. But all the injuries are not serious; we don't pay much attention to them. They will be ok in 1 or 2 days. (Female, 25s, store monitor)

Besides, it is a common sense that the rate of demission is very high in convenience stores. One reason for this is that the staffs' salary is too low. In Beijing, the hourly pay for part-time employees in convenience stores is only 9 or 12 yuan. Even for the full time employees, their monthly pay is about 2000 yuan, which is much lower than the average salary in Beijing. Another reason maybe is that they don't have a good vocational development. One part- time employee sees the job in the convenience store as follows:

\begin{abstract}
I don't want to be a full time employee after I graduate. You have to do a lot of work here, but the salary is very low. Despite these, you don't have a better prospect. Yeah, you may be promoted form salesclerk to store monitor, then assistant store manager and manager store manager. After becoming a store manager, you may open a franchise store by yourself. But that is too difficult. Moreover, I think the managerial rule is kind of unfair. I really can't understand why we college students do the same work as the social workers, but their salary is higher than us. Anyway, I can accept the job here as a part-time job, but not my full time job, not my career. (Female, 20s, part-time)
\end{abstract}

\title{
5 Conclusions and Further Directions
}

The research illustrates that the work in convenience store is not only labor intensive, but also needs mental skills and emotional skills. We found that there are some potential human factors and ergonomics issues in the experience of the staffs. (1) Physiological human factors: they have to handle materials every day and it is easy for them to be injured; they have to work graveyard shift and get very exhausted and sleepy and suffer a danger to health. (2) Cognitive human factors: they have to work under stress and make quick and flexible responses to varied emergencies and reluctant customers; they must bear the complaint, rudeness, disrespect and unreasonableness of customers; they have to put up with the repletion, bore and monotonity of their job. (3) Organizational human factors: their hourly/monthly pay is much lower than the average salary in Beijing; they don't have a good occupational prospect; they are unsatisfied with the unfair wages rules.

For future research, we can explore solutions to these existent issues. Meanwhile, it is critical to analyze the interaction between the frontline service employees and customer as well as the experience of the customers in convenience stores. Further research may use questionnaire and experiment to evaluate the experience of both the employees and the customers. Then meaningful countermeasures and suggestions could be given to improve the experience in convenience and set up a systematic service design based on experience.

Acknowledgments. This research was funded by a 2009 young researcher grant from Asia Research Center in Tsinghua University. We would like to thank the INSIGHT Center for their suggestions for sections of this paper. 


\section{References}

1. Hao, W.: Study on Development Strategy of Beijing Convenience Store. Capital University of Economics and Business, Beijing (2007)

2. Rafaeli, A.: When Cashier Meet Customers: An Analysis of the Role of Supermarket Cashiers. The Academy of Management Journal 32, 245-273 (1989)

3. Mohr, L.A., Bitner, M.J.: The Role of Employee Effort in Satisfaction with Service Transactions. Journal of Business Research 32, 239-252 (1995)

4. Ailawadi, K.L., Beauchamp, J.P., Naveen, D.G., Venkatesh, S.: Customer Experience Management in Retailing: Communication and Promotion. Journal of Retailing 85, 10-12 (2009)

5. Frow, P., Payne, S.A.: Towards the 'Perfect' CustomerExperience. Journal of Brand Management 15(2), 89-101 (2007)

6. Tausky, C.: The meanings of work. Research in the Sociology of Work 5, 15-27 (1995)

7. Jane, E.D.: Crafting a job: Revisioning employees as an active crafter of their work. Academy of Management 26(2), 179-201 (2001)

8. Hanny, N.N., Felix, T.M.: Customer value in the hotel industry: What managers believe the deliver and what customer experience. International Journal of Hospitality Management 27, 204-213 (2008)

9. Leonard, L.B., Lewis, P.C., Stephan, H.H.: Managing the Total Customer Experience. Management Review 43(3), 112-118 (2002)

10. Fletcher, J.K.: Relational practice: A feminist recon structure of work. Journal of Management Inquiry 7, 163-186 (1998) 